\title{
Field Isolates of Streptomyces Differ in Pathogenicity and Virulence on Radish
}

\author{
Leslie A. Wanner, United States Department of Agriculture-Agricultural Research Service, Vegetable Laboratory, \\ Beltsville, MD 20705
}

\begin{abstract}
Wanner, L. A. 2004. Field isolates of Streptomyces differ in pathogenicity and virulence on radish. Plant Dis. 88:785-796.

Common scab is a significant disease of potato, and affects root and tuber crops worldwide. Streptomycetes, a diverse group of soil-inhabiting gram-positive bacteria, cause common scab. To better understand the basis for variability in disease symptoms seen in field situations, streptomycetes were isolated from scabby potato plants. Isolates differed in morphology and pigmentation. Isolates were evaluated for pathogenicity and virulence in radish. Scab lesions varied in appearance and severity. Disease symptoms also included plant stunting, wilting, necrosis, and death. Some pathogenic isolates were missing genes from the putative pathogenicity island (PAI); several lacked the necl gene, and one was missing the txtA gene encoding thaxtomin biosynthesis, the most reliable pathogenicity determinant. Studies of disease severity over $5 \operatorname{logs}$ initial inoculum density showed that there is a threshold inoculum density for disease. Disease severity increased with inoculum density over three logs, then reached a maximum, which is characteristic of individual Streptomyces strains. Lesion severity was not correlated with presence of melanin, the necl gene, or whether an isolate reduced seedling emergence or plant survival. Differences in disease symptoms and severity combined with absence of known pathogenicity determinants $(t x t A)$ or factors $(n e c 1)$ suggest that there may be pathogenicity factors in addition to thaxtomin.
\end{abstract}

Additional keywords: phytotoxicity; Raphanus sativus

Common scab is an important potato disease, reducing the quality of tubers, sometimes to the point that they no longer can be sold. Common scab also affects other tuber and root crops, including radish, beet, carrot, turnip, and sweet potato, where it may produce considerable economic losses. Incidence and severity of common scab on potato are variable from year to year, field to field, and cultivar to cultivar. Reasons for this variability are not well understood, although environmental factors, including soil moisture and soil $\mathrm{pH}$, and differences in cultivar susceptibility have been described $(29,31,35,36)$.

Common scab is caused by soil-inhabiting gram-positive filamentous bacteria in the group known as streptomycetes. Of the hundreds of species of soil streptomycetes, few are known to be pathogenic on plants. At least 10 different species of Streptomyces and related Kitosatospora can produce

Corresponding author: L. Wanner

E-mail: wannerl@ba.ars.usda.gov

Accepted for publication 22 March 2004.

Publication no. D-2004-0601-03R

This article is in the public domain and not copyrightable. It may be freely reprinted with customary crediting of the source. The American Phytopathological Society, 2004 common scab in potato $(3,11,23,31)$, and at least three additional Streptomyces spp. produce potato netted or russet scab $(3,12)$. Streptomycetes causing potato scab are morphologically and phylogenetically diverse, differing in numerous morphological and physiological characteristics $(4,5,13,23,24,28,31), 16 \mathrm{~S}$ rDNA sequences $(3,5,11,23,41)$, and cellular fatty acid profiles $(22,28)$, and differing extensively in restriction fragment length polymorphism and repetitive element-polymerase chain reaction (PCR) patterns $(11,38)$.

Scab diseases of underground tuber or root crops are the most widely recognized disease symptoms caused by streptomycetes, but fibrous root rots, root tumors, and phytotoxic effects on seedlings have been described $(3,10,21,26,31,32)$. Published cross-species data are limited but it is thought that the same streptomycetes are pathogens on all host root and tuber crops, including radish (15), with the apparent exception of sweet potato $(10,31)$. Streptomycetes isolated from potato scab lesions previously have been shown to infect radish $(14,15,27)$, though one isolate from radish was not pathogenic on potato (27). Differences in the aggressiveness of individual Streptomyces isolates have been described in both potato and in radish (Raphanus sativus) $(2,14,19,33)$, although inoculation densities seldom were re- ported. There is little available information on the mechanisms of variation in pathogen aggressiveness, or how this impacts the incidence or severity of common scab disease in the field.

Most plant-pathogenic streptomycetes make at least one of a group of phytotoxins, called thaxtomins $(1,10,25,31)$. The cyclic dipeptide toxin thaxtomin is considered a pathogenicity determinant. Genes for thaxtomin biosynthesis are located in a region of the Streptomyces chromosome distinguished by a different G/C composition (6-8), and hence reminiscent of a pathogenicity island (PAI). The PAI is not completely defined in Streptomyces spp., but is proposed to include a gene for a putative pathogenicity factor (necl) at one end, and genes encoding biosynthesis of thaxtomin at the other end $\operatorname{txt} A B$ and $t x t($ ), several hundred kilobase pairs distant (9). In $S$. turgidiscabies, this region appears to extend more than $400 \mathrm{~kb}$. A mechanism for spread of plant pathogenicity via the horizontal transfer of the PAI into distantly related streptomycetes to produce new plant-pathogenic strains recently has been proposed $(6,8)$.

The main objectives of this study were to (i) compare the pathogenicity (diseasecausing potential) and virulence or aggressiveness (severity of disease caused) of individual Streptomyces isolates collected from scabby potato plants and (ii) associate aggressiveness of pathogenic isolates with known molecular disease determinants, including the presence of the necl and txtA genes. The longer-term goals of this research are to gain insight into why the severity of disease is different from one disease-causing Streptomyces strain to another, and to gain information about pathogenic isolates that can be used to develop methods of predicting the suitability of a field for cultivation of scab-free root and tuber crops.

\section{MATERIALS AND METHODS}

Streptomyces isolates and culture conditions. The 61 Streptomyces isolates used in this study are listed in Table 1. Type strains of S. scabiei ATCC 49173, S. scabies var. achromogenes ATCC 33281, S. scabiei ATCC 33282 (neotype strain), and S. acidiscabies ATCC 49003, all causing common scab on potato, were obtained from the American Type Culture Collec- 
Table 1. Sources and some characteristics of isolates used in this study

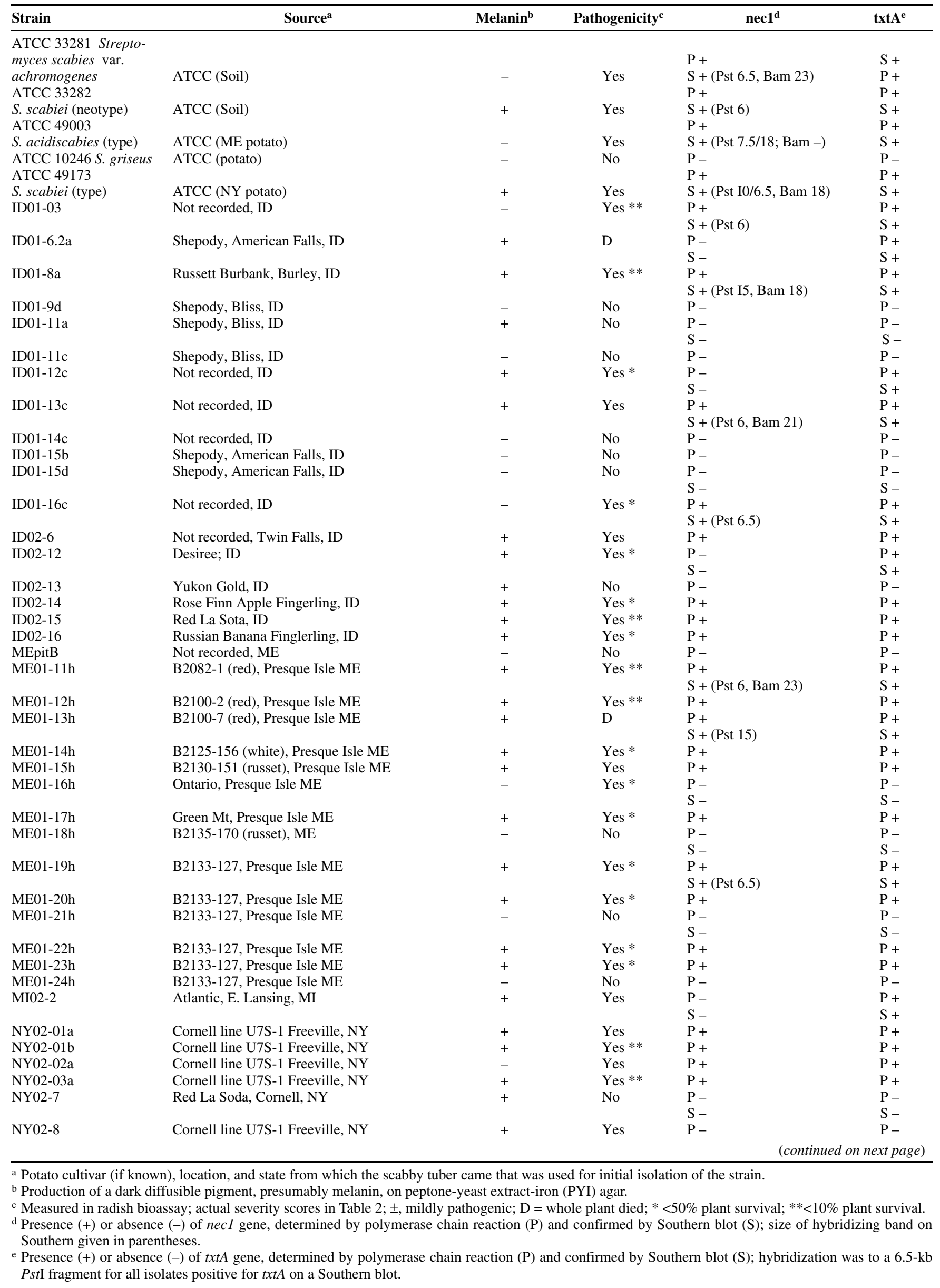


Table 1. (continued from preceding page)

\begin{tabular}{|c|c|c|c|c|c|}
\hline Strain & Source $^{a}$ & Melanin $^{b}$ & Pathogenicity & $\operatorname{nec1}^{d}$ & $\operatorname{txtA}^{\mathrm{e}}$ \\
\hline NY02-18 & Cornell line U7S-1 Freeville, NY & + & Yes * & $\mathrm{P}+$ & $\mathrm{P}+$ \\
\hline NE01-3 & Atlantic, NE & - & No & $\begin{array}{l}\mathrm{P}- \\
\mathrm{S}-\end{array}$ & $\begin{array}{l}\mathrm{P}- \\
\mathrm{S}-\end{array}$ \\
\hline NE02-17 & Not recorded, Scottsbluff, NE & + & Yes * & $\mathrm{P}+$ & $\mathrm{P}+$ \\
\hline $\mathrm{OH} 01-5 \mathrm{a}$ & Yukon Gold, Urbana, OH & + & Yes * & $\begin{array}{l}P+ \\
S+(\text { Pst 6, Bam 23) }\end{array}$ & $\begin{array}{l}\mathrm{P}+ \\
\mathrm{S}+\end{array}$ \\
\hline $\mathrm{OH} 01-5.2$ & Yukon Gold, Urbana, $\mathrm{OH}$ & + & Yes * & $\begin{array}{l}\mathrm{P}+ \\
\mathrm{S}+(\text { Pst } 6)\end{array}$ & $\begin{array}{l}\mathrm{P}+ \\
\mathrm{S}+\end{array}$ \\
\hline $\mathrm{OH} 01-5 \mathrm{~d}$ & Yukon Gold, Urbana, OH & + & Yes & $\begin{array}{l}\mathrm{P}+ \\
\mathrm{S}+(\text { Pst } 6)\end{array}$ & $\begin{array}{l}\mathrm{P}+ \\
\mathrm{S}+\end{array}$ \\
\hline $\mathrm{OH} 01-6 \mathrm{a}$ & Reba, Urbana, OH & + & Yes $* *$ & $\begin{array}{l}\mathrm{P}+ \\
\mathrm{S}+(\text { Pst 6, Bam 23) }\end{array}$ & $\begin{array}{l}\mathrm{P}+ \\
\mathrm{S}+\end{array}$ \\
\hline OH01-6.2a & Reba, Urbana, $\mathrm{OH}$ & + & Yes & $\begin{array}{l}P+ \\
S+(\text { Pst } 6)\end{array}$ & $\begin{array}{l}\mathrm{P}+ \\
\mathrm{S}+\end{array}$ \\
\hline $\mathrm{OH} 01-11 \mathrm{c}$ & B1752-5, Urbana, OH & - & No & $\mathrm{P}-$ & $\mathrm{P}-$ \\
\hline $\mathrm{OH} 01-12 \mathrm{c}$ & Reba, Urbana, OH & + & Yes ** & $\begin{array}{l}P+ \\
S+(\text { Pst 6, Bam 23) }\end{array}$ & $\begin{array}{l}\mathrm{P}+ \\
\mathrm{S}+\end{array}$ \\
\hline WI02-1 & Frito Lay numbered variety, Rhinelander, WI & + & \pm & $\begin{array}{l}\mathrm{P}- \\
\mathrm{S}-\end{array}$ & $\begin{array}{l}\mathrm{P}- \\
\mathrm{S}-\end{array}$ \\
\hline WI02-4 & Russett, Plover, WI & + & Yes & $\mathrm{P}+$ & $\mathrm{P}+$ \\
\hline WI02-5 & Yukon Gold, Sturgeon Bay, WI & + & Yes & $\mathrm{P}+$ & $\mathrm{P}+$ \\
\hline WI02-9 & Not recorded, Hancock, WI & + & No & $\mathrm{P}-$ & $\mathrm{P}-$ \\
\hline WI02-11 & Not recorded, Rhinelander, WI & + & Yes * & $\mathrm{P}+$ & $\mathrm{P}+$ \\
\hline
\end{tabular}

tion (ATCC; Manassas, VA). S. griseus ATCC 10246 is not pathogenic on potato. Field isolates were obtained from scab lesions on potato tubers. Scabby potato plants were collected from seven states in the United States and 20 different potato cultivars. A small tuber piece containing a scab lesion was cut out and surface disinfected in $1.5 \%$ Clorox bleach for 1 to 2 min. After several rinses in sterile distilled water, the tissue was ground in a groundglass homogenizer in $5 \mathrm{ml}$ of sterile water. Serial dilutions were plated onto water agar plates (2\% agar). Plates were incubated at $28^{\circ} \mathrm{C}$, and individual characteristic powdery (mycelial) bacterial colonies were picked and serially transferred until a pure culture was obtained. In some cases, the original homogenate was heated for 30 min at $55^{\circ} \mathrm{C}$ before serial dilution and plating; this reduced the background of rapidly growing rhizobacteria. Yeast-malt extract (YME) or YME agar (39) was used for routine culture of Streptomyces strains. Peptone-yeast extract-iron (PYI) agar (39) was used for determination of production of dark, diffusible melanoid pigments. Colony and spore color was assessed after 2 weeks on YME plates. Strains were maintained as spore suspensions in $20 \%$ glycerol at -20 or $-80^{\circ} \mathrm{C}$, or as agar plugs cut from actively growing plates, and stored at $-80^{\circ} \mathrm{C}$.

Inoculum. A procedure modified from Goyer and Beaulieu (15) was used to produce inoculum for plant inoculation. YME $(50 \mathrm{ml})$ in a $250-\mathrm{ml}$ Erlenmeyer flask was inoculated with $1,000 \mu \mathrm{l}$ of a suspension of spores harvested in water from a 2- to 3week-old plate of Streptomyces spp. grown on YME agar. Spores were counted on a hemocytometer slide, and adjusted to $10^{6}$ $\mathrm{CFU} / \mathrm{ml}$ to inoculate flasks. Cultures were grown for 3 days, with shaking, at $28^{\circ} \mathrm{C}$. Cells were pelleted by centrifugation and resuspended in $\mathrm{dH}_{2} \mathrm{O}$. Resuspended 3-dayold culture $(8 \mathrm{ml})$ and $100 \mathrm{ml}$ of sterile Say's solution (20 $\mathrm{g}$ of sucrose, $1.2 \mathrm{~g}$ of asparagine, $0.6 \mathrm{~g}$ of $\mathrm{K}_{2} \mathrm{HPO}_{4}$, and $10 \mathrm{~g}$ of yeast extract in 1 liter of $\mathrm{dH}_{2} \mathrm{O}$ ) was added to $300 \mathrm{ml}$ of sterile vermiculite. Vermiculite for culture of soil inoculum was wetted with $50 \mathrm{ml}$ of water per $300 \mathrm{ml}$ and sterilized by autoclaving in $300-\mathrm{ml}$ portions, three times for $90 \mathrm{~min}$ each, at 2-day intervals before inoculation with Streptomyces spore suspensions. Inoculated vermiculite was incubated for 14 days at $28^{\circ} \mathrm{C}$ and was mixed in the bags every other day during incubation. After 14 days, a 1-ml sample of vermiculite was removed, suspended in $9 \mathrm{ml}$ of sterile $\mathrm{dH}_{2} \mathrm{O}$, incubated with shaking for $30 \mathrm{~min}$, and four replicate $10-\mu \mathrm{l}$ samples of dilutions $\left(10^{-2}, 10^{-3}, 10^{-4}, 10^{-5}\right)$ were plated onto YME medium. Plates were incubated at $28^{\circ} \mathrm{C}$ for 2 days, and colonies were counted to ensure that only Streptomyces spp. were present in the inoculum, and to quantify and compare inoculum concentrations used in different experiments. Typically, $2.5 \times 10^{8} \mathrm{CFU} / \mathrm{g}$ of vermiculite was obtained, which was diluted 1:10 (vol/vol) with sterile sand:soil for plant growth. This translates into $1.8 \times$ $10^{10} \mathrm{CFU}$ of Streptomyces spp. per pot. For the inoculum density dilution series, 14day-old vermiculite cultures were prepared and quantified as above, and the concentration of streptomycetes was adjusted to $10^{7}$ $\mathrm{CFU} / \mathrm{g}$ with additional sterile vermiculite. Adjusted inoculum was diluted 1:9 with sterile sand:soil for the highest inoculum concentration. One volume of this mixture then was diluted with nine volumes of sand:soil to prepare the $10^{6} \mathrm{CFU} / \mathrm{g}$ inoculum. This procedure was repeated until five 10 -fold dilutions of inoculum were obtained.

Plant growth and infection. Pots (15 $\mathrm{cm})$ were partly filled with $600 \mathrm{ml}$ of a
50:50 mixture of sterile sand:potting soil (Jiffy Mix Plus; Jiffy Products of America, Batavia, IL). Vermiculite inoculum (300 $\mathrm{ml}$ ) was added to $3,000 \mathrm{ml}$ of 50:50 sterile sand:Jiffy Mix Plus and mixed thoroughly. Inoculum-containing mixture $(1,200 \mathrm{ml})$ then was overlaid in each pot. Radish seed (Raphanus sativus cv. Cherriette F1; Johnny's Selected Seeds, Albion, ME) were surface sterilized $(0.5 \%$ bleach for 3 min), rinsed several times in sterile distilled water, and planted directly into the inoculum-containing layer, 9 to 10 seeds per pot. Radish plants were grown in a Conviron growth chamber at $24^{\circ} \mathrm{C}$, with a 14-h photoperiod, $200 \mu$ moles $\mathrm{m}^{-2}$ under Philips natural daylight fluorescent lights. Plants were thinned to nine plants per pot as evenly spaced as possible, and watered when soil moisture declined to $1 \%$, as judged by weighing the pots to determine water loss. This was approximately every 4 to 5 days, starting 1 week after germination, and becoming more frequent as plants grew. Soil started out at $50 \%$ of field capacity (about $0.4 \mathrm{MPa}$ ) and dried to near the wilting point (1.5 MPa), then was watered to $50 \%$ of field capacity. Radish hypocotyls were harvested and scored for scab after 5 weeks (35 days).

Disease scoring. Scab lesions were rated on all scorable radish plants after 5 weeks of growth in inoculated soil. The average number of scorable radish hypocotyls in uninoculated control plants was 15.3 (out of a possible total of 27); the corresponding average number of radish hypocotyls from soil inoculated with ATCC 49173 that could be rated in 14 experiments was 14.5. Radish hypocotyls were scored on a scale of 0 to 5 , where $0=$ no lesion, 1 = discrete superficial lesions less than $10 \mathrm{~mm}$ in diameter, $2=$ coalescing superficial lesions more than $10 \mathrm{~mm}$ in diameter, 3 = raised lesions less than 10 
$\mathrm{mm}$ in diameter, $4=$ coalescing raised lesions more than $10 \mathrm{~mm}$ in diameter, and $5=$ pitted or sunken lesions. All radish hypocotyls with a diameter at the widest point larger than $0.5 \mathrm{~cm}$ were rated, and an average calculated; each pot was considered an experimental unit. Data presented are averages of all replicate pots in an experiment, or the average of averages of all experiments done with a single isolate. The y-error bars are the average standard deviation of all experiments with an isolate, and show the experimental variability. There are y-error bars only for isolates tested in more than one independent experiment; therefore, there is no error bar for some isolates that were tested in separate experiments if scorable radish hypocotyls were not obtained in more than one experiment. Isolates producing an average lesion severity score of less than 1.0 were considered nonpathogenic on radish. A score of 6 was assigned to isolates that killed all radish plants in an experiment for graphic display, but this score was not used in calculating standard errors. In most cases, data are averaged from two experiments, each containing three replicate pots of nine plants. Data for 21 of the 61 isolates evaluated came from single experiments (three replicate pots, nine plants each). Data for the inoculum dilution series came from two experiments, each experiment with three isolates inoculated onto four replicate pots of nine plants each; strain ATCC 49173 was used in both
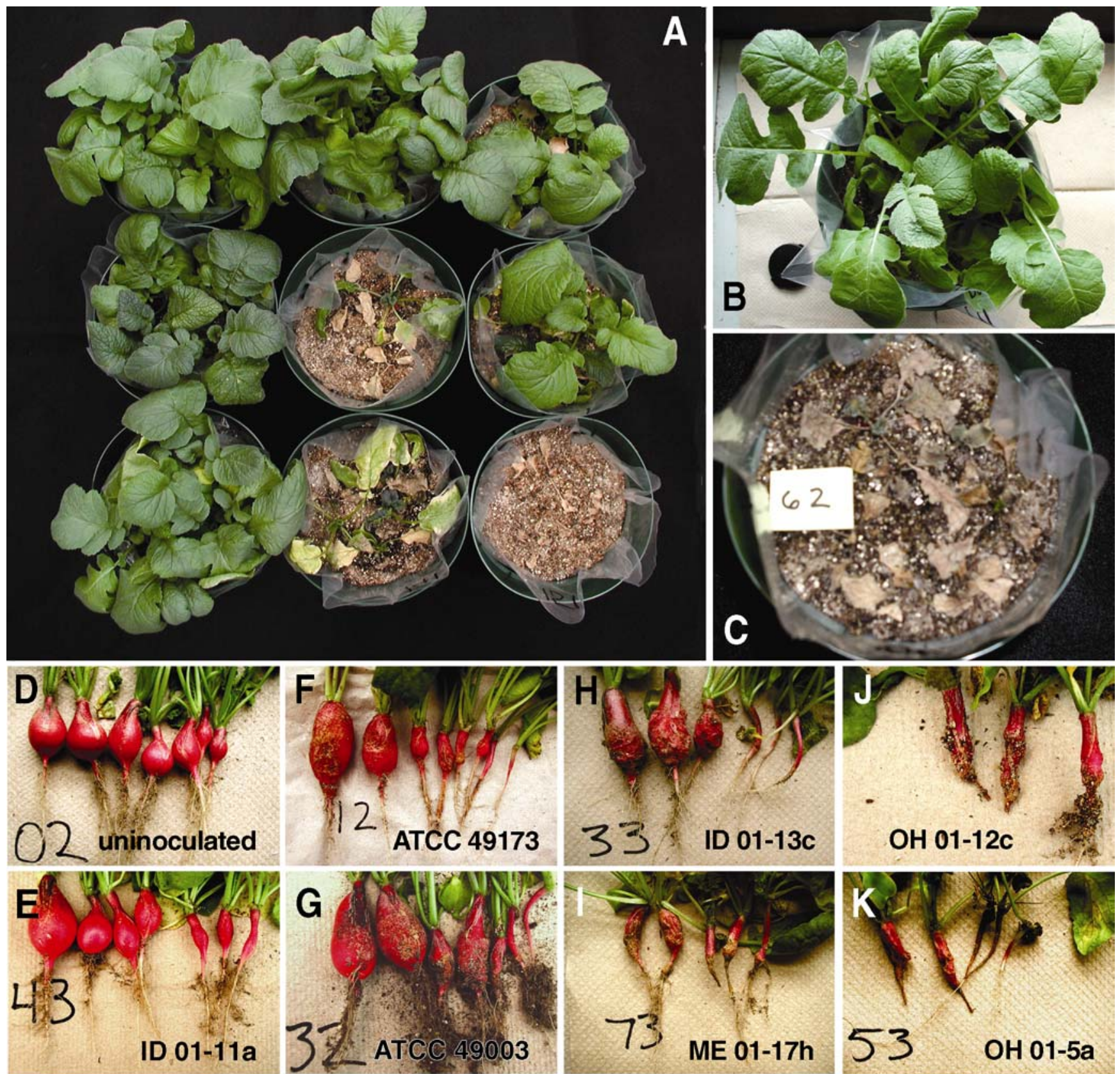

Fig. 1. Individual Streptomyces isolates differentially affect radish emergence, survival, and scab lesion severity. Disease parameters and inoculation densities used for each isolate are listed in Table 2. A, Variation in plant appearance and survival 5 weeks after sowing in inoculated soil. Each pot was inoculated with a different Streptomyces isolate, and planted with nine radish seeds. Isolates from upper left across to right (1-3), middle left to right (4-6), and bottom left to right (7-9) are 1, not inoculated; 2, MI02-1; 3, ATCC 49173; 4, ID02-6; 5, WI02-11; 6, ID02-12; 7, ID02-13; 8, ID02-14; and 9, ID02-15. B, Close up of healthy noninoculated plants. C, Close up of radish planted in soil inoculated with isolate ID01-8a. Plants germinated and grew for 2 to 3 weeks, then died. D-K, Appearance of radish plants inoculated with different Streptomyces isolates. Plant leaves appeared healthy in D through I. Plant leaves were necrotic, stunted, dying, or dead in J and K. D and E show radish with no scab disease. D, uninoculated; E, ID01-11a. F and G show radish plants that developed normally but had scab lesions; F, S. scabiei ATCC 49173; G, S. acidiscabies ATCC 49003. H and I show radish plants that were inhibited in their development and had scab lesions; H, ID01-13c; I, ME01-17h. J and K show severely affected radish hypocotyls from plants that were stunted, necrotic, and dying or dead. J, OH01-12c; K, OH01-5a. 
experiments to verify consistency between experiments. Data from the water-treated plants (uninoculated control) are averages of 15 experiments, and data from strain ATCC 49173 are averages of 14 experiments.

Determination of the presence of the necl and $t x t A$ genes and their genomic context. For DNA isolation, Streptomyces cultures were grown at $28^{\circ} \mathrm{C}$ for 3 days in YME, and cells were pelleted and stored frozen until use. DNA was extracted from approximately $100 \mathrm{mg}$ of frozen cells using a Bio101 FAST DNA kit (sphere plus garnet beads and CLS-Y lysing solution) and a Qbiogene Fast Prep machine (settings: speed 5.0, time $25 \mathrm{~s}$ ). DNA was eluted from columns in $2 \times 50 \mu \mathrm{l}$ of $10 \mathrm{mM}$ Tris-HCl (pH 9.0), and 0.2 mM EDTA. Quantity and integrity of DNA preparations were checked on agarose gels, and suitability of DNA preparations for PCR amplification was verified by amplifying the 16S rRNA genes.

PCR primers were purchased from Integrated DNA Technologies (Coralville, IA). Sequences of primers used to amplify bacterial $16 \mathrm{~S}$ rRNA were $16 \mathrm{~S}-1 \mathrm{~F}=5^{\prime}$ CATTCACGGAGAGTTTGATCC-3' and $16 \mathrm{~S}-1 \mathrm{R}=5^{\prime}$-AGAAAGGAGGTGATCC AGCC-3' (8); to amplify nec 1 , Nec1F = 5'ATGAGCGCGAACGGAAGCCCCGGA$3^{\prime}$ and Nec1R = 5'GCAGGTCGTCACGA AGGATCG-3' (6); and to amplify $t x t A$, TxtA1 = 5'-CACGTACGCGCAGTTCA ATG-3' $3^{\prime}$ and TxtA2 $=5^{\prime}$-AGATGATGT AGGCGGGACTC-3'. The txtA primers were selected with the help of the program Primer 3 (37) from sequence data for $S$. acidiscabies thaxtomin synthetase $\mathrm{AB}$ (GenBank accession number AF255732) (18). PCR reactions contained $10 \mathrm{mM}$ Tris- $\mathrm{HCl}$ (pH 9.0), $50 \mathrm{mM} \mathrm{KCl,} 0.1 \%$ Triton X-100, $1.5 \mathrm{mM} \mathrm{MgCl}_{2}(2 \mathrm{mM}$ $\mathrm{MgCl}_{2}$ for necl; $1 \mathrm{mM} \mathrm{MgCl}_{2}$ for $t x t A$ ), $200 \mu \mathrm{M}$ each dNTP, 25 pmol each primer, $2.5 \mathrm{U}$ Taq DNA polymerase (Promega Corp., Madison, WI), 2 to $25 \mathrm{ng}$ of DNA template (usually $1 \mu \mathrm{l}$ of a 1:9 dilution), and MilliQ water in a final volume of 50 $\mu$ l. Amplification was carried out in a Perkin-Elmer Thermal Cycler 480 or a GeneAmp PCR System 9600 programmed for one initial denaturation step at $95^{\circ} \mathrm{C}$ for 5 min followed by 40 or 42 cycles of denaturing at $95^{\circ} \mathrm{C}$ for $20 \mathrm{~s}$; annealing at $55^{\circ} \mathrm{C}$ for $16 \mathrm{~S}$ rRNA, $60^{\circ} \mathrm{C}$ for $n e c 1$, and $48^{\circ} \mathrm{C}$ for $t x t A$ for $30 \mathrm{~s}$; and extension at $72^{\circ} \mathrm{C}$ for 2 min, and ending with a $4^{\circ} \mathrm{C}$ hold.

The amplified DNA was separated on a $1.5 \%$ agarose gel to verify the size and presence of the expected 1,500-bp $16 \mathrm{~S}$ rDNA, 700-bp necl, or 398-bp txtA fragments. PCR amplification experiments were repeated at least twice with two independently cultured and isolated DNA template preparations for each Streptomyces isolate.

Presence or absence of txtA and necl genes was confirmed by Southern blotting for many isolates (Table 1). For restriction digestions, Fast Prep DNA preparations were further cleaned using a Gen-Elute PCR Clean-up Kit (Sigma-Aldrich, St. Louis) to improve restriction digestion efficiency. Eluted DNA was quantified by comparison with known quantities of $\lambda$ HindIII fragments on agarose gels, and equal amounts of DNA were digested with PstI or BamHI (Promega Corp.) according to the manufacturer's recommendations. Restriction-digested DNA preps were size separated on $0.8 \%$ agarose Tris-acetate EDTA gels, stained with ethidium bromide, and transferred by capillary action overnight to Amersham Hybond N+ filters using an alkaline transfer procedure, according to the protocol accompanying Amersham Hybond N+. Filters were baked for $2 \mathrm{~h}$ at $80^{\circ} \mathrm{C}$ and wrapped in plastic film until use. Prehybridization $(2 \mathrm{~h})$ and hybridization ( 20 to $22 \mathrm{~h}$ ) were carried out at $65^{\circ} \mathrm{C}$ in $2 \times \mathrm{SSC}(1 \times \mathrm{SSC}$ is $0.15 \mathrm{M} \mathrm{NaCl}$ plus $0.015 \mathrm{M}$ sodium citrate), $0.5 \%$ blocking reagent (Roche Diagnostics, Indianapolis, IN), $5 \%$ dextran sulfate, $0.1 \%$ sodium dodecyl sulfate (SDS), and denatured fish sperm DNA at $50 \mu \mathrm{g} / \mathrm{ml}$. After hybridization, filters were washed for $1 \mathrm{~min}$ in $2 \times \mathrm{SSC} / 1 \% \mathrm{SDS}$, followed by $15 \mathrm{~min}$ of $65^{\circ} \mathrm{C}$ in $2 \times \mathrm{SSC} / 1 \% \mathrm{SDS}$ and $30 \mathrm{~min}$ of $65^{\circ} \mathrm{C}$ in $0.2 \times \mathrm{SSC} / 1 \%$ SDS.

DNA probes used were the 400-bp txtA and the 700-bp necl PCR fragments. For labeling, PCR fragments were excised and eluted from agarose gels using a Zymoclean Gel DNA Recovery Kit (Zymo Research, Orange, CA). Isolated DNA fragments were labeled using a NEN Renaissance random primer fluorescein labeling kit. Unincorporated nucleotides were removed using Amersham ProbeQuant G50 spin columns, and chemiluminescent detection of hybridized products was carried out using antifluorescein-AP conjugate and the NEN CDP-Star Nucleic Acid Chemiluminescence Reagent, all according to manufacturer's directions. Kodak X-OMAT Blue film was exposed for 5 or $10 \mathrm{~min}$ to detect hybridization.

\section{RESULTS}

Description of streptomycetes isolated from scabby potato plants. Streptomycetes were isolated from scabby potato plants collected from at least 20 different potato cultivars from three locations in Idaho, five in Wisconsin, three in New York, and one location each in Ohio, Maine, Michigan, and Nebraska (Table 1). The original scabby tubers showed a range of symptoms from superficial small discrete lesions covering parts of a tuber to large, deep, coalescing raised or pitted lesions covering most or all of a tuber. The isolates obtained varied in their growth rate and habit in solid and liquid culture, colony color and morphology, color of spores, and production of diffusible pigments. They also varied in their pathogenicity on radish (Figs. 1 and 2) and on two potato cultivars (unpublished data), and in the molecular features of the putative PAI.

Variation in pathogenicity and virulence on radish. Sixty-one isolates were assayed for pathogenicity by planting radish (cv. Cherriette F1) in soil inoculated with cultures of individual streptomycetes, and scoring for the type and extent of lesions on radish hypocotyls after 5 weeks of growth. Scab symptoms produced by different isolates varied from few or no lesions to brown, pitted, necrotic areas covering much or all of the surface of the radish (Fig. 1D to $1 \mathrm{~K}$ ). Lesion severity was scored from 0 to 5 . There was some damage or cracking of uninfected radish hypocotyls so that radish plants from noninoculated control pots had an average lesion severity score of $0.57 \pm 0.35$; therefore, isolates producing average lesion severity scores of less than 1.0 were considered nonpathogenic. Lesion severity was reproducible when the same isolate was tested in independent experiments, and seems to be characteristic of an isolate. Four type or neotype strains of S. scabies, $S$. scabiei, and $S$. acidiscabies obtained from the ATCC were included as reference strains (Table 1). These strains are known to cause common scab on potato, and all four of these strains caused scab on radish, with lesion severity scores of 3.0 to 3.4 . The average lesion severity for $S$. scabiei ATCC 49173 in 14 independent experiments was 3.18 .

Of the isolates tested, 43 had lesion severity scores greater than 1.0 and were classified as pathogenic, and 16 caused no discernable difference in symptoms compared with no inoculum or with ATCC 10246, a nonpathogenic S. griseus strain (Fig. 2A). Two isolates had average lesion scores close to 1.0, making their classification as pathogens ambiguous. Two pathogenic strains were mildly virulent, with lesion severity scores between 1.0 and 2.0. Most isolates, like the S. scabiei and S. acidiscabies strains, had lesion severity scores between 3.0 and 4.0. Scores for five isolates were between 2.0 and 3.0, and scores were greater than 4.0 for 10 isolates. All plants were killed by two of the isolates.

The isolates are arranged according to the average severity of scab lesions they cause in Figure 2A. However, the lesion severity scores shown actually are based on widely differing numbers of scorable radish hypocotyls obtained after inoculating pots with different isolates (Table 2). The reason for this is that, in addition to causing scab lesions on radish hypocotyls, Streptomyces isolates affected plant emergence, survival, and hypocotyl development, resulting in widely varying numbers of radish plants with hypocotyls larger than $0.5 \mathrm{~cm}$ in diameter that could be scored for scab.

Additional symptoms on plants. In addition to superficial, raised, or pitted scab 

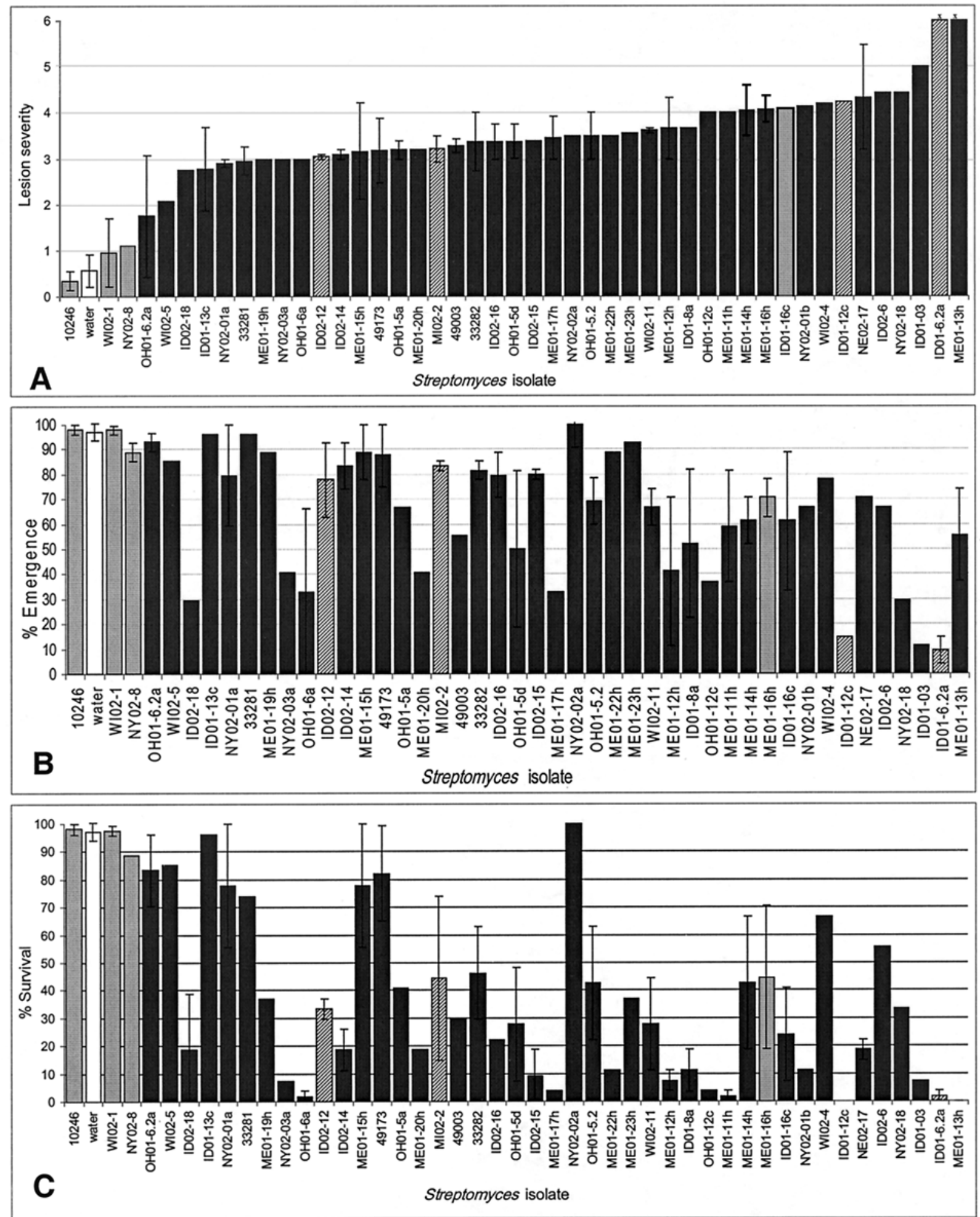

Fig. 2. Comparison of scab lesion severity, seedling emergence, and plant survival of radish plants grown in soil inoculated with different pathogenic Streptomyces isolates. A, Scab lesion severity scores of Streptomyces isolates. Lesions were rated after 5 weeks of growth; bars represent average scores of all scorable radishes. In most cases, data are averages of two or more independent experiments each containing three replicate pots of nine plants, and average standard deviation for multiple independent experiments is shown by the y-error bars. Data from the water-treated plants (uninoculated control) are averages of 15 experiments (each with three pots of nine plants), and data from strain ATCC 49173 are averages of 14 experiments. Plants were scored on a scale of 0 to 5 (see Materials and Methods). A score of 6 was assigned to the isolates that killed all radish plants in an experiment (far right two bars), but this score was not used in calculating standard errors. A representative nonpathogenic strain (ATCC 10246) and the uninoculated water control (open bar) are displayed on the left. Most pathogenic isolates contained both the necl and txtA genes (solid bars). Some pathogenic strains contained txtA but not necl (thick slanted stripes), and one pathogenic isolate contained neither the txtA nor the necl gene (horizontal stripes). B, Some Streptomyces isolates reduce radish seedling emergence. Bars represent the average percent emergence of seedlings. In most cases, data are averages from two independent experiments; the average standard deviation of multiple experiments is shown by the y-error bars. Isolates are arranged in the same order as in A, from least to most severe scab lesions. The bars are filled in as in A: horizontal stripes, absence of txtA and necl; slanted stripes, txtA only; solid bars, presence of both $t x t A$ and necl. The open bar is a noninoculated (water) control. $\mathbf{C}$, Some isolates reduced radish seedling survival, either by reducing seedling emergence or by killing the plants after they had grown for 2 to 5 weeks. Streptomyces isolates are arranged in the same order and the bars are filled as in A. The isolate furthest to the right killed all plants in two independent experiments. 
lesions covering differing proportions of the surface of radish hypocotyls, other symptoms were produced by some isolates. These included inhibition of hypocotyl (radish) expansion, distortion of the expanding hypocotyl, dwarfing and discoloration of leaves, and necrosis and death of entire plants (Fig. 1A and C). Many Streptomyces isolates reduced radish plant emergence or survival (Figs. 1A and 2B and C). Fifty-eight isolates were evaluated for their effect on plant emergence. Emergence included germination plus early growth until plants appeared above the soil. In 15 independent experiments with

Table 2. Disease parameters produced by Streptomyces isolates and strains on radish

\begin{tabular}{|c|c|c|c|c|c|c|}
\hline \multirow[b]{2}{*}{ Strain $^{\mathbf{a}}$} & \multirow[b]{2}{*}{ Scorable $(\exp )^{b}$} & \multicolumn{3}{|c|}{ Average } & \multicolumn{2}{|c|}{ Log inoculation density ${ }^{d}$} \\
\hline & & Scab lesion score $(\mathrm{SD})^{\mathrm{c}}$ & Emergence \% (SD) ${ }^{c}$ & Survival \% (SD) ${ }^{\mathrm{c}}$ & $\operatorname{Exp} 1$ (low) & Exp 2+ (high) \\
\hline WI02-9 & $17(1)$ & 0.06 & 100.0 & 100.0 & 6.92 & $\ldots$ \\
\hline ID01-11a & $17(1)$ & 0.29 & $\ldots$ & $\ldots$ & 9.05 & $\ldots$ \\
\hline ID01-15b & $16(1)$ & 0.31 & $\ldots$ & $\ldots$ & 8.95 & $\ldots$ \\
\hline 10246 & $34(2)$ & $0.35(0.21)$ & $98.1(1.85)$ & $98.1(1.85)$ & 8.28 & 8.62 \\
\hline ID01-11c & $14(1)$ & 0.36 & 100.0 & 100.0 & 9.01 & $\ldots$ \\
\hline MEpitB & $16(1)$ & 0.37 & 100.0 & 100.0 & 8.01 & $\ldots$ \\
\hline ID01-14c & $16(1)$ & 0.38 & $\ldots$ & $\ldots$ & 9.05 & $\ldots$ \\
\hline ME01-18h & $18(1)$ & 0.38 & 100.0 & 100.0 & 9.00 & $\ldots$ \\
\hline ID01-15d & $31(2)$ & $0.38(0.18)$ & 92.6 & 92.6 & 8.51 & 8.45 \\
\hline ME01-24h & $17(1)$ & 0.47 & 100.0 & 100.0 & 6.86 & $\ldots$ \\
\hline NE01-3 & $16(1)$ & 0.50 & 96.3 & 96.3 & 7.55 & $\ldots$ \\
\hline ID02-13 & $30(2)$ & $0.54(0.07)$ & $100.0(0.00)$ & $100.0(0.00)$ & 7.26 & 7.49 \\
\hline water & $249(15)$ & $0.57(0.35)$ & $97.2(3.30)$ & $97.2(3.30)$ & $\ldots$ & $\ldots$ \\
\hline ME01-21h & $35(2)$ & $0.59(0.17)$ & $98.1(1.85)$ & $98.1(1.85)$ & 9.00 & 8.86 \\
\hline NY02-7 & $17(1)$ & 0.65 & 96.3 & 96.3 & 8.26 & $\ldots$ \\
\hline ID01-9d & $36(2)$ & $0.66(0.19)$ & 100.0 & 100.0 & 9.06 & 9.15 \\
\hline $\mathrm{OH} 01-11 \mathrm{c}$ & $33(2)$ & $0.72(0.05)$ & $94.4(5.56)$ & $94.4(5.56)$ & 8.44 & 8.85 \\
\hline WI02-1 & $48(3)$ & $0.96(0.74)$ & $97.5(1.75)$ & $97.5(1.75)$ & 7.37 & 8.94 \\
\hline NY02-8 & $10(1)$ & 1.10 & 88.9 & 88.9 & 8.63 & $\ldots$ \\
\hline OH01-6.2a & $33(2)$ & $1.75(1.33)$ & $92.6(3.70)$ & $83.3(12.96)$ & 5.10 & 6.04 \\
\hline WI02-5 & $12(1)$ & 2.08 & 85.2 & 85.2 & 8.54 & $\ldots$ \\
\hline ID02-18 & $4(1)$ & 2.75 & 29.6 & 18.5 & 8.48 & $\ldots$ \\
\hline ID01-13c & $29(2)$ & $2.78(0.91)$ & 96.3 & 96.3 & 5.79 & 7.81 \\
\hline NY02-01a & $24(2)$ & $2.92(0.09)$ & $79.6(20.37)$ & $77.8(22.22)$ & 7.83 & 8.70 \\
\hline 33281 & $35(2)$ & $2.96(0.30)$ & 96.3 & 74.1 & 6.69 & 6.74 \\
\hline ME01-19h & $10(1)$ & 3.00 & 88.9 & 37.0 & 7.83 & $\ldots$ \\
\hline NY02-03a & $2(1)$ & 3.00 & 40.7 & 7.4 & 8.37 & $\ldots$ \\
\hline OH01-6a & $1(2)$ & 3.00 & $33.3(33.33)$ & $1.9(1.85)$ & 8.16 & 8.29 \\
\hline ID02-12 & $13(2)$ & $3.05(0.05)$ & $77.8(14.81)$ & $33.3(3.70)$ & 7.56 & 8.35 \\
\hline ID02-14 & $7(2)$ & $3.10(0.10)$ & $83.3(9.26)$ & $18.5(7.41)$ & 7.27 & 7.82 \\
\hline ME01-15h & $27(2)$ & $3.17(1.06)$ & $88.9(11.11)$ & $77.8(22.22)$ & 7.19 & 8.66 \\
\hline 49173 & 217 (14) & $3.18(0.70)$ & 87.7 (12.59) & $82.1(17.03)$ & 7.18 & 8.47 \\
\hline OH01-5a & $20(2)$ & $3.20(0.20)$ & 66.7 & 40.7 & 6.34 & 8.48 \\
\hline ME01-20h & $5(1)$ & 3.20 & 40.7 & 18.5 & 8.18 & $\ldots$ \\
\hline MI02-2 & $16(2)$ & $3.22(0.29)$ & $83.3(1.85)$ & $44.4(29.63)$ & 8.16 & 8.69 \\
\hline 49003 & $25(2)$ & $3.29(0.15)$ & 55.6 & 29.6 & 7.24 & 7.28 \\
\hline 33282 & $19(2)$ & $3.37(0.64)$ & $81.5(3.70)$ & 46.3 (16.67) & 7.06 & 7.22 \\
\hline ID02-16 & $10(2)$ & $3.38(0.38)$ & $79.6(9.26)$ & $22.2(0.00)$ & 6.82 & 7.16 \\
\hline OH01-5d & $10(2)$ & $3.38(0.38)$ & $50.0(31.48)$ & $27.8(20.37)$ & 6.76 & 8.43 \\
\hline ID02-15 & $5(2)$ & 3.40 & $79.6(1.85)$ & $9.3(9.26)$ & 7.52 & 7.79 \\
\hline ME01-17h & $16(2)$ & $3.47(0.47)$ & 33.0 & 3.7 & 8.62 & 7.71 \\
\hline NY02-02a & $18(1)$ & 3.50 & 100.0 & 100.0 & 8.14 & $\ldots$ \\
\hline OH01-5.2 & $9(2)$ & $3.50(0.50)$ & $68.5(9.26)$ & $42.6(20.37)$ & 7.45 & 8.20 \\
\hline ME01-22h & $2(1)$ & 3.50 & 88.9 & 11.1 & 6.76 & $\ldots$ \\
\hline ME01-23h & $7(1)$ & 3.57 & 92.6 & 37.0 & 6.41 & $\ldots$ \\
\hline WI02-11 & $12(2)$ & $3.62(0.05)$ & $66.7(7.41)$ & $27.8(16.67)$ & 8.40 & 8.70 \\
\hline ME01-12h & $4(2)$ & $3.67(0.67)$ & 40.7 (29.63) & $7.4(3.70)$ & 8.82 & 8.84 \\
\hline ID01-8a & $3(2)$ & 3.67 & $51.9(29.63)$ & $11.1(7.41)$ & 8.33 & 8.81 \\
\hline $\mathrm{OH} 01-12 \mathrm{c}$ & $4(2)$ & 4.00 & 37.0 & 3.7 & 7.64 & 8.85 \\
\hline ME01-11h & $1(2)$ & 4.00 & $59.3(22.22)$ & $1.9(1.85)$ & 8.04 & 8.05 \\
\hline ME01-14h & $15(2)$ & $4.05(0.55)$ & $61.1(9.26)$ & $42.6(24.07)$ & 8.01 & 8.41 \\
\hline ME01-16h & $16(2)$ & $4.08(0.28)$ & $70.4(7.41)$ & $44.4(25.93)$ & 4.37 & 7.31 \\
\hline ID01-16c & $11(2)$ & 4.09 & $61.1(27.78)$ & $24.1(16.67)$ & 7.62 & 7.96 \\
\hline NY02-01b & $3(1)$ & 4.14 & 66.7 & 11.1 & 7.76 & $\ldots$ \\
\hline WI02-4 & $10(1)$ & 4.20 & 77.8 & 66.7 & 7.43 & $\ldots$ \\
\hline ID01-12c & $4(2)$ & 4.25 & 14.8 & 0.0 & 7.97 & 8.25 \\
\hline NE02-17 & $9(2)$ & $4.34(1.14)$ & $70.4(0.00)$ & $18.5(3.70)$ & 6.44 & 7.74 \\
\hline ID02-6 & $9(1)$ & 4.44 & 66.7 & 55.6 & 8.10 & $\ldots$ \\
\hline NY02-18 & $8(1)$ & 4.44 & 37.0 & 33.3 & 8.07 & $\ldots$ \\
\hline ID01-03 & $1(1)$ & 5.00 & 11.1 & 7.4 & 8.50 & $\ldots$ \\
\hline ID01-6.2a & $0(2)$ & D & $9.3(5.56)$ & $1.9(1.85)$ & 8.36 & 8.81 \\
\hline ME01-13h & $0(2)$ & $\mathrm{D}$ & $55.6(18.52)$ & $0.0(0.00)$ & 8.12 & 8.25 \\
\hline
\end{tabular}

a Arranged according to increasing scab lesion severity scores; first 18 isolates classified as nonpathogenic (lesion severity score $<1.0$ ).

b Total scorable radish plants (number of independent experiments).

c $\mathrm{SD}=$ standard deviation of the population in parentheses.

${ }^{\mathrm{d}} \log$ of the lowest and highest initial inoculum concentrations (in CFU/g of vermiculite) used in experiments. 
noninoculated control plants, seedling emergence averaged 97\% (Fig. 2B). Seedling emergence of radish plants exposed to isolates classified as nonpathogens based on scab lesion severity was greater than $90 \%$, and the average was $98 \%$. In contrast, the average emergence percentage of radish plants exposed to isolates classified as pathogens was $64 \%$, but the range was from $9 \%$ to $100 \%$. The average seedling emergence for S. scabiei ATCC 49173 in 14 independent experiments was $88 \%$. Seedling emergence was greater than $80 \%$ in the presence of the other S. scabies or $S$. scabiei type strains and for 14 of the pathogenic field isolates. The S. acidiscabies type strain (ATCC 49003) reduced seedling emergence to $55 \%$. In general, isolates causing more severe scab lesions also reduced seedling emergence to a greater, but variable, extent, but there were a few isolates producing severe scab lesions that had no effect on seedling emergence or survival (e.g., NY02-02a and ME01-23h; Fig. 2B and C, Table 2). Two isolates severely reduced seedling emergence to $11 \%$ or less (ID01-03 and ID01$6.2 a)$.

Some Streptomyces isolates caused chlorosis, necrosis, and, ultimately, death of plants that emerged and grew normally for 2 to 4 weeks (Figs. 1C and 2C). For noninoculated plants and for all nonpathogenic isolates, the average 5-week plant survival was the same as seedling emergence, $98 \%$. For pathogenic isolates, the average 5 -week survival was $35 \%$, with a range of 0 to $100 \%$. In some cases, there was no difference between seedling emergence and 5-week survival but, for most isolates, there was a further reduction in plant survival during 5 weeks. Survival of radish plants inoculated with $S$. scabiei ATCC 49173 was $82 \%$, and with S. acidiscabies ATCC 49003, 30\%. For several isolates, few or no plants survived after 5 weeks (e.g., OH01-6a, ME01-17h, OH0112c, ID01-12c, ID01-6.2a, ME01-13h, and ME01-11h). Estimations of scab lesion severity were necessarily limited by lack of scorable radish plants for these isolates. Plant survival at 5 weeks was relatively reproducible, and seems to be characteristic of the isolate.

Hypocotyl development was sometimes impaired in inoculated radish plants with foliage that was healthy and indistinguishable from noninoculated plants (Fig $1 \mathrm{H}$ and I). Other isolates produced stunted plants with chlorotic or necrotic foliage and severely underdeveloped radish hypocotyls (Fig. 1J and K).

Inoculum concentrations. An obvious question is whether the differences in severity of scab lesions, inhibition of seedling emergence, or chlorosis, necrosis, and plant death at later stages are primarily a function of the concentration of Streptomyces present in the soil. To examine the role of inoculum density in severity of scab lesions, seedling emergence, and plant survival, radish plants were grown in a series of initial inoculum densities covering five logs. Five different Streptomyces isolates were used. These were selected based on differences in disease severity in initial experiments at high inoculum density. Strain ATCC 49173 produced an average scab lesion severity score and little reduction in seedling emergence or later plant survival. Isolate ID01-13c had a lower lesion severity score and higher plant emergence and survival than ATCC 49173. Isolate OH01-5a had a lesion severity score similar to ATCC 49173, but reduced seedling emergence and survival. Isolate ME01-11h had a higher lesion severity score and lower seedling emergence and survival than ATCC 49173, and radish plants grown in soil inoculated with isolate ID01-6.2a showed severely reduced seedling emergence and plant survival and no radish hypocotyl development. There were very few or no scab lesions (lesion severity scores of less than 1.0) in radish plants grown in pots inoculated with any of the Streptomyces isolates at $10^{3} \mathrm{CFU} / \mathrm{g}$, the lowest inoculum density used (Fig. 3A). Seedling emergence and plant survival were not affected at this inoculum density. At a 10-fold higher inoculum density, scab lesions were produced by all five strains (Fig. 3A). Lesions were most severe for isolate ID01-6.2a and least severe with ATCC 49173 and ID01-13c. The difference in severity became more pronounced as inoculum concentration was increased over two more logs. At inoculum densities of $10^{6} \mathrm{CFU} / \mathrm{g}$ of vermiculite or higher, isolate ID01-6.2a killed the plants, and OH01-5a produced a lesion severity score of 5.0 (Fig. 3A). For strain ATCC 49173, the lesion severity score averaged 3.25 for all inoculum concentrations of $10^{6} \mathrm{CFU} / \mathrm{g}$ or higher, up to $3 \times 10^{8} \mathrm{CFU} / \mathrm{g}$, the highest inoculum concentration tested in any experiment (Fig. 3A and data not shown). Severity scores for the other two isolates also remained at approximately 3.0 for initial inoculum concentrations of $10^{5}$ $\mathrm{CFU} / \mathrm{g}$ or higher.

Seedling emergence also was affected by initial inoculum densities (Fig. 3B). Seedling emergence was reduced in ID016.2a and $\mathrm{OH} 01-5 \mathrm{a}$ at inoculum concentrations of $10^{6}$ or greater, and in ME01-11h and ID01-13c at $10^{7} \mathrm{CFU} / \mathrm{g}$, but an inoculum density of $10^{8}$ was required to see a reduction in seedling emergence produced by ATCC 49173 (data not shown). Effects on long-term plant survival were evident at lower initial inoculum densities (Fig. 3C). ID01-6.2a reduced plant survival at an initial inoculum concentration of $10^{4}$ $\mathrm{CFU} / \mathrm{g}$ of vermiculite, and $\mathrm{OH} 01-5 \mathrm{a} \mathrm{did}$ so at $10^{5} \mathrm{CFU} / \mathrm{g}$. In contrast, an initial inoculum concentration of at least $10^{8}$ $\mathrm{CFU} / \mathrm{g}$ was required to see a sporadic effect on plant survival with strain ATCC 49173.
To assess the pathogenicity and virulence of the field isolates, we attempted to standardize the production of inoculum so that the same initial concentrations were used in every experiment. The average inoculum concentration was $2.5 \times 10^{8}$ $\mathrm{CFU} / \mathrm{g}$ in vermiculite cultures. In most cases, inoculum densities in independent experiments with the same isolate differed by less than $1 \log$. These initial inoculum densities were high compared with the threshold inoculum densities required to produce disease symptoms in the dilution series experiments. The data from the dilution series also showed that there was no further effect of a 10-fold increase in inoculum density on scab lesion severity score when the initial inoculum density was greater than $10^{6}$ to $10^{7} \mathrm{CFU} / \mathrm{g}$, though plant emergence and 5-week survival continued to diminish as the initial inoculum density increased. Based on these results, we expect that the initial inoculum densities used in assessing pathogenicity and virulence in the field isolates were high enough to produce the maximum severity of scab symptoms characteristic of an isolate.

The actual initial inoculum densities used are shown in Table 2. It can be seen that the most pathogenic isolates were not necessarily present at the highest inoculum densities. Some isolates that produced severe scab lesions and significantly reduced plant survival were present at the lowest concentrations (e.g., ME01-22h and ME01-23h). Most of the nonpathogenic isolates were present at high initial inoculum concentrations of approximately $10^{9}$ $\mathrm{CFU} / \mathrm{g}$ of vermiculite. Although the effect of a wide range of different initial inoculum densities was not examined for most field isolates, we conclude that the variation in lesion severity, reduction in seedling emergence, or longer-term phytotoxicity produced by the pathogenic isolates represents the difference in virulence characteristic of individual isolates, and are not likely to be an effect of inoculum density alone.

Production of melanoid pigments. Production of melanoid pigments (melanin) often has been used as a marker for pathogenicity in soil streptomycetes $(19,24)$, although it has been widely reported that pathogenic streptomycetes may not produce melanin, and many nonpathogenic strains do $(5,13,19,23,41)$. In the present collection of 61 Streptomyces isolates tested for pathogenicity on radish, 42 produced a dark, diffusing pigment, presumably a melanin, on an iron-agar medium (Table 1). Though most $(70 \%)$ nonpathogenic isolates did not produce melanin, and most (86\%) pathogenic isolates did produce melanin, 4 of 17 isolates clearly nonpathogenic on radish produced melanin, 2 that were very mildly or ambiguously pathogenic produced melanin, and 5 of 42 pathogenic isolates, including 
S. scabies var. achromogenes ATCC 33281 and S. acidiscabies ATCC 49003, did not produce melanin. Isolates producing a dark diffusible pigment on iron-agar medium also produced a dark pigment under standard liquid and vermiculite culture conditions.

Presence of the txtA gene and conserved structure of the thaxtomin gene region. All nonpathogenic isolates were missing genes for biosynthesis of thaxtomin (Fig. 2A-C; Table 1), as tested by PCR using primers from the $t x t A$ gene. All except one of the pathogenic isolates (ME01-16h) had the expected 398-bp txtA gene fragment. Presence or absence of the txtA gene was confirmed by Southern blotting for 27 isolates using a 398-bp portion of the $t x t A$ gene as a probe; in all cases, PCR and Southern results corresponded. In all $20 t x t A$-positive isolates examined on Southern blots, hybridization was to an approximately $6.5-\mathrm{kb} \quad P s t \mathrm{I}$ fragment, roughly consistent with the reported $4.9-\mathrm{kb}$ PstI fragment incorporating txtA (18).

Presence of the necl gene and structure of the nec1 gene region. Nonpathogenic isolates did not have the necl gene, while most pathogenic isolates had the expected 700-bp necl gene fragment, as tested by PCR using primers amplifying the necl gene (8). Presence or absence of the necl gene in all of the isolates is shown in Table 1 and indicated on Figure 2. Of 43 pathogenic isolates, 5 were missing the necl gene fragment. Presence or absence of the necl gene was confirmed by Southern blotting for 28 isolates, using a 700-bp portion of the necl gene as a probe (Table 1). In all cases, PCR and Southern results corresponded. Of 17 necl-positive isolates, five different patterns of bands on Southern blots were seen when DNA was digested with Pst $\mathrm{I}$, and three different patterns were seen with BamHI-digested DNA (Table 1). Further evidence for sequence diversity in this region of the Streptomyces genome was obtained using PCR anchored in the necl gene, or in an open reading frame located immediately $5^{\prime}$ to the necl gene, ORFtnp (data not shown). It appears that this region of the PAI is somewhat variable, both in its presence in pathogenic isolates and in its detailed molecular structure.

\section{DISCUSSION}

In this collection of 56 new streptomycetes isolated from scabby potato plants, there is diversity in morphology, pigment production, molecular characteristics of the PAI, pathogenicity, and virulence. Isolates differed in features traditionally associated with pathogenicity, such as production of a dark melanoid pigment, and one isolate lacks a gene needed for biosynthesis of the most thoroughly studied pathogenicity determinant, the phytotoxin thaxtomin. In all, 39 isolates were pathogenic on radish and 17 were not. We expected to
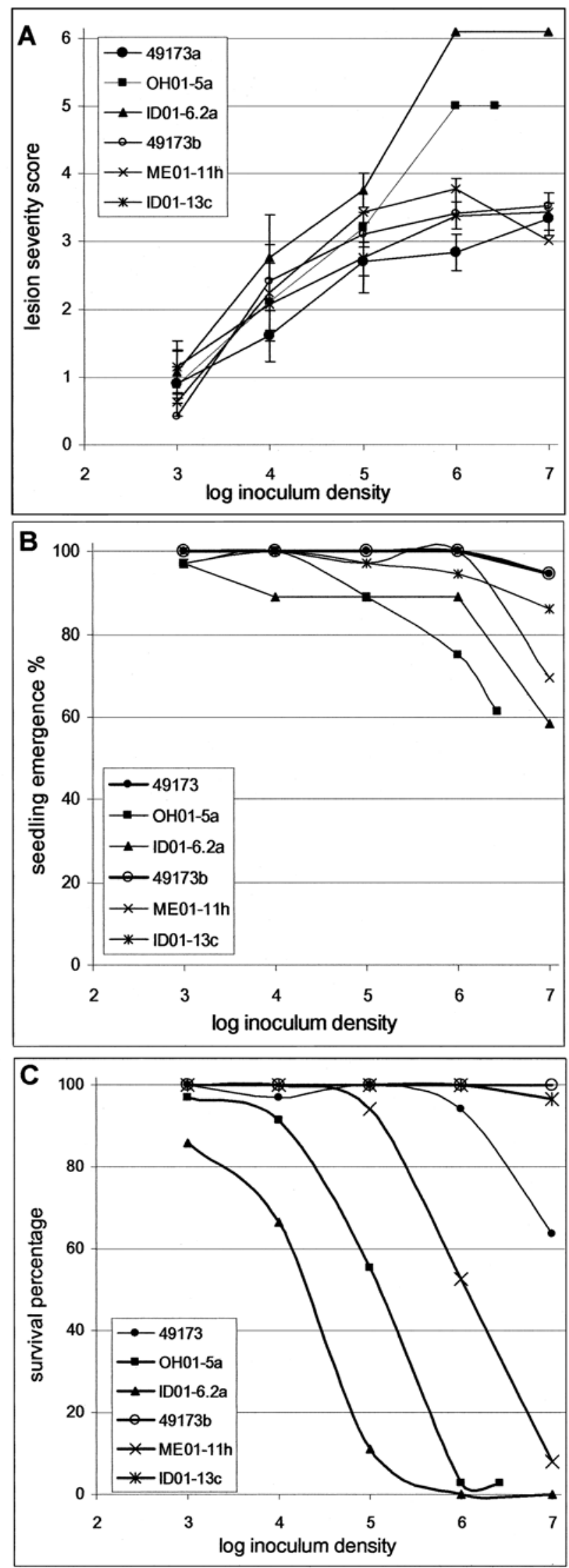

Fig. 3. Effect of initial inoculum concentration on scab lesion severity, seedling emergence, and plant survival. A, Scab lesion severity scores plotted against the log of the inoculum density for five Streptomyces strains. Plants were killed at an inoculum density of $10^{6}$ or higher with isolate ID01-6.2a. The highest inoculum density attained with $\mathrm{OH} 01-5 \mathrm{a}$ was $3 \times 10^{6} \mathrm{CFU} / \mathrm{g}$ of vermiculite. Strain ATCC 49173 was included in two experiments $(-$ and $\bigcirc)$. B, Seedling emergence plotted against the log of the inoculum density for the five isolates shown in A. C, Plant survival after 5 weeks plotted against the $\log$ of the inoculum density; isolates as in A. 
recover nonpathogens as well as pathogens, because streptomycetes, mostly not plant pathogenic, are extremely abundant in soils, and some of these soil saprophytes are likely to co-inhabit scab lesions. Others have reported that $55 \%$ of streptomycetes isolated from scabby potato tuber lesions were pathogenic (27). Differences in virulence were manifested as scab lesion phenotypes on radish, including both differences in numbers and severity of lesions, and in phytotoxicity, measured as reduced emergence of seedlings or chlorosis, necrosis, and death of leaves after a few weeks of growth.

We expected that streptomycetes isolated from potato would be pathogenic on radish. Of the 34 isolates we tested for pathogenicity on both radish and potato, all were pathogenic on radish, and 33 were pathogenic on two potato cultivars (unpublished data). The observation that streptomycetes pathogenic on potato generally are pathogenic on radish is convenient, because it validates the use of a radish assay for rapidly assessing the pathogenicity and virulence of isolates. Radish plants grow more quickly and take less space than potato plants, and the time and effort required for the radish bioassay compares favorably with a widely used potato minituber assay $(1,22,25,28,30)$. The radish assay also provides additional data on seedling and plant toxicity.

One potential source of variability in disease incidence and severity was the initial pathogen load. An inoculum concentration series spanning $5 \operatorname{logs}$ was set up to examine the importance of this. Scab lesion severity and phytotoxicity to seedlings and plants were evaluated after exposure to five Streptomyces isolates. At the lowest inoculum concentration, there was no disease produced by any of these isolates. Scab lesions were mild at a 10-fold higher inoculum density, became more severe as the initial inoculum density was increased over $3 \operatorname{logs}$, and then reached a plateau; further increases in inoculum density produced no further increase in lesion severity. The maximum lesion severity score was higher in one isolate (OH01-5a) that was more virulent than the $S$. scabies type strain (ATCC 49173). At inoculum concentrations higher than the threshold for scab lesions, seedling emergence, and survival were reduced by the most virulent isolates. The concentration at which seedling survival began to decline was more than 100fold lower for the two most virulent field isolates than for ATCC 49173 and the other less virulent isolates. Plants were killed without production of enlarged radish hypocotyls at $10^{5} \mathrm{CFU} / \mathrm{g}$ of inoculum for the most virulent isolate (ID01-6.2a). We conclude that initial inoculum density is a major determinant of disease development. Our results are in accord with those of Keinath and Loria, who reported that potato tuber scab severity, as measured by percentage of area covered, increased with the $\log$ of the inoculum concentration over a range of initial inoculum of approximately $4 \operatorname{logs}(20)$. These researchers also found that rhizosphere populations of Streptomyces increased 2 to $3 \operatorname{logs}$ during the 4-month experiments when the initial inoculum concentration was high, although this was not true at low initial inoculum concentrations. We measured initial inoculum density only, and have no data on how the inoculum density changed over the course of our 5-week experiments.

We could discern variation in the extent and severity of scab lesions, in the reduction in seedling emergence, and in later phytotoxicity when individual isolates were inoculated at high initial inoculum concentrations in the radish bioassay. The isolates studied in a series of initial inoculum densities showed maximal symptom severity at concentrations lower than those used in the comparison of field isolates; therefore, we expect that the inoculum density used was high enough to produce maximum disease symptoms for most or all of the isolates. We conclude that the differences in symptom severity we saw at high initial inoculum density reflect differences in virulence. We do not know how the inoculum densities used in our experiments relate to the density of pathogenic streptomycetes typically found in field soil.

Interestingly, this collection of isolates showed substantial phytotoxicity in the radish bioassay. Phytotoxicity could occur either early in development, affecting seedling emergence, or later in development, affecting long-term plant survival. There was no strict relationship between scab lesion severity scores and emergence or survival of plants. Some isolates that produced mildly or moderately scabby lesions greatly reduced plant emergence (e.g. ID02-18), whereas others produced severely scabby radish hypocotyls, but did not reduce seedling emergence or survival compared with noninoculated plants (e.g., NY02-02a). Emergence and survival percentages generally were reproducible in independent experiments with an isolate. The lethality of an isolate and whether plants die early or late in development appear to be characteristic features of the isolate. More research is needed to understand whether these two forms of phytotoxicity are the result of differences in pathogenicity or virulence factors in different Streptomyces isolates.

S. scabies and S. scabiei strains probably are the most abundant pathogenic Streptomyces spp. in soils; they have been most frequently characterized and described $(13,23,24,31)$. The $S$. scabiei, $S$. scabies, and $S$. acidiscabies strains used as references and most of the field isolates produced similar lesion severity scores of between 3.0 and 4.0. Only three isolates produced significantly more mild scab than ATCC 49173, with lesion scores less than
2.0, and 12 produced lesion severity scores greater than 4.0. The S. scabies and $S$. scabiei reference strains were less typical in the degree of phytotoxicity they caused; 28 of the 39 pathogenic isolates in this collection reduced seedling emergence and plant survival more than ATCC 49173, and 34 were more phytotoxic than ATCC 33281. Though no effect of pathogenic soil streptomycetes on radish plant stand has been reported, this appears to be a possibility. Some isolates that are phytotoxic on radish also produced chlorosis or necrosis in potato foliage, and inhibited tuber set (unpublished data). It appears that strains much more virulent than the type species of $S$. scabies and S. acidiscabies are to be found on scabby potato plants, and that they may be more typical. Extensive sampling in selected areas will be necessary to determine whether the more virulent strains are most abundant in particular fields.

The production of thaxtomin is a highly reliable marker for plant pathogenicity in streptomycetes $(17,18)$, and assays of thaxtomin production in vitro are quantitatively correlated with virulence on potato $(17,22,31)$. All except one of the isolates that were pathogenic on radish had the $t x t A$ gene, one of a cluster of genes encoding enzymes for the peptide synthetase responsible for biosynthesis of this phytotoxic pathogenicity determinant. Researchers in Korea recently have reported two streptomycetes causing potato scab that did not produce thaxtomin (34).

Purified thaxtomin can reproduce necrosis and the tissue hypertrophy symptoms of common scab on potato tubers, and it also produced necrosis at the site of application on potato, tomato, beet, and raspberry leaves (16). Lack of seedling emergence produced by thaxtomin has been noted by King, and thaxtomin inhibits radish and Arabidopsis sp. seedling growth and development $(25,26,31,40)$. These effects of pure thaxtomin are similar to the symptoms produced by some of our Streptomyces isolates on radish. However, it also has been shown by King that thaxtomin is not transported in plants, and its toxic effects are not systemic (21). Chlorosis, necrosis, wilting, and death of aboveground parts of the plant were produced by some isolates. This could be explained by thaxtomin damage to belowground portions of the plant, or by transportable phytotoxic products of Streptomyces infections.

Others have suggested that pathogenicity factors or determinants in addition to thaxtomin may be involved in disease etiology caused by streptomycetes. Kinkel et al. noted that $60 \%$ of the variation in disease severity on tubers was attributable to thaxtomin levels, leaving $40 \%$ to be accounted for by other factors (22). Leiner et al. (26) showed data indicating that Streptomyces cultures produce more symptoms on seedlings than culture supernatants, 
suggesting that additional virulence or phytotoxicity components could be present. Thaxtomin apparently acts as an inhibitor of cellulose biosynthesis $(21,40)$, but some differences in the effects of thaxtomin and of other cellulose biosynthesis inhibitors have been noted (21), particularly that cellulose biosynthesis inhibitors do not typically produce wilting. Whether all of the necrotic and phytotoxic effects of our Streptomyces isolates on radish plants can be attributed to thaxtomin remains to be experimentally verified.

Other putative pathogenicity factors that have been reported in streptomycetes causing common scab include production of a dark, diffusible pigment on iron-containing media (melanin), and the presence of necl, a gene that converts a nonpathogenic $S$. lividans strain to a strain that can produce necrotic lesions on potato tuber discs (6-8). In our collection, melanin production was not always correlated with pathogenicity. Though $88 \%$ of pigmented streptomycetes were pathogenic, 4 of 42 pathogenic isolates lacked melanin, and isolates that did not produce melanin covered the full spectrum of scab lesion severity, seedling emergence percentage, and seedling survival percentage. Also, several nonpathogenic isolates did produce melanin. This is consistent with the observations of others that production of melanin is not a reliable indicator of pathogenicity $(5,13,23,41)$.

The necl gene has been reported to be present within a conserved genomic region resembling a PAI in the majority of pathogenic strains of $S$. scabiei, S. acidiscabies, and $S$. turgidiscabies $(6,8)$. The compound causing necrosis that is produced by neclcontaining strains or transformants has not been identified, but it is distinct from thaxtomin (7). Necl was not found in any nonpathogenic isolate in our collection, and was present in the majority of pathogenic isolates. However, the five isolates lacking necl showed a spectrum of scab lesion severity, seedling emergence percentage, and seedling survival percentage, so it is not obvious what role this pathogenicity factor might play in virulence. The absence of necl previously has been noted in one of a collection of 43 pathogenic $S$. scabies isolates from the United States, Japan, Hungary, and South Africa (6), and in three pathogenic Korean isolates (34). The absence of necl in 5 of 39 pathogenic isolates examined here suggests that this may be more common in the United States than has been reported. The necl gene region was missing in Finnish potato scabcausing strains classified as $S$. turgidiscabies and $S$. aureofaciens based on $16 \mathrm{~S}$ rRNA gene sequence and physiological characteristics (23). Isolates in the present collection have not been phylogenetically classified to Streptomyces sp. based on 16S rRNA sequences.

We have collected streptomycetes from potato scab lesions that show a range in virulence phenotypes on radish. We found that initial inoculum density was a primary determinant of all symptoms of radish disease caused by streptomycetes. Differences in densities of the population of scab-causing streptomycetes in the soil seem likely to contribute to differences in incidence and severity of scab seen in the field. Symptoms included lesions on radish hypocotyls and phytotoxicity, both to seedlings and in older plants. The radish assay enabled us to rapidly determine the pathogenicity and virulence of field isolates. Pathogenic isolates generally had the $t x t A$ gene for thaxtomin biosynthesis, but an isolate apparently missing this pathogenicity determinant suggests the possibility of additional pathogenicity determinants to be discovered. Work is continuing to identify additional molecular features of the bacteria that correlate with their disease-causing potential and the severity of disease they cause. Further research on changes in pathogen populations over time, the effects of pathogen concentrations in soils, and the presence and effect of competitors or antagonists in field situations can contribute to understanding variability in scab incidence and severity. Molecular markers are being developed to facilitate tracing the spread of individual pathogenic strains and for quantifying pathogenic streptomycetes in soils.

\section{ACKNOWLEDGMENTS}

I thank M. Elson for excellent technical assistance; and K. Haynes, D. Kelly, and J. Miller for scabby potato tubers.

\section{LITERATURE CITED}

1. Babcock, M. J., Eckwall, E. C., and Schottel, J. L. 1993. Production and regulation of potato-scab-inducing phytotoxins by Streptomyces scabies. J. Gen. Microbiol. 139:1579-1586.

2. Bång, H. 1979. Studies on potato russet scab. I. a characterization of different isolates from northern Sweden. Acta Agric. Scand. 29:145150.

3. Bouchek-Mechiche, K., Gardan, L., Normand, P., and Jouan, B. 2000. DNA relatedness among strains of Streptomyces pathogenic to potato in France: description of three new species, S. europaeiscabiei sp. nov. and S. stelliscabiei sp. nov. associated with common scab, and $S$. reticuliscabiei sp. nov. associated with netted scab. Int. J. Syst. Evol. Microbiol. 50:91-99.

4. Bouchek-Mechiche, K., Guerin, C., Jouan, B., and Gardan, L. 1998. Streptomyces species isolated from potato scabs in France: numerical analysis of "Biotype-100" carbon source assimilation data. Res. Microbiol. 149:653-663.

5. Bramwell, P. A., Wiener, P., Akkermans, A. D., and Wellington, E. M. 1998. Phenotypic, genotypic and pathogenic variation among streptomycetes implicated in common scab disease. Lett. Appl. Microbiol. 27:255-260.

6. Bukhalid, R. A., Chung, S. Y., and Loria, R. 1998. necl, a gene conferring a necrogenic phenotype, is conserved in plant-pathogenic Streptomyces spp. and linked to a transposase pseudogene. Mol. Plant-Microbe Interact. 11:960-967.

7. Bukhalid, R. A., and Loria, R. 1997. Cloning and expression of a gene from Streptomyces scabies encoding a putative pathogenicity factor. J. Bacteriol. 179:7776-7783.
8. Bukhalid, R. A., Takeuchi, T., Labeda, D., and Loria, R. 2002. Horizontal transfer of the plant virulence gene, nec1, and flanking sequences among genetically distinct Streptomyces strains in the Diastatochromogenes cluster. Appl. Environ. Microbiol. 68:738-744.

9. Cameron, K. D., Kers, J. A., Joshi, M., Julotok, M., and Loria, R. 2003. Characterization of a mobile pathogenicity island in Streptomyces turgidiscabies, a pathogen of potato. (Abstr.) Phytopathology 93:S13.

10. Clark, C. A., Chen, A., Ward-Rainey, N., and Pettis, G. S. 1998. Diversity within Streptomyces ipomoeae based on inhibitory interactions, REP-PCR, and plasmid profiles. Phytopathology 88:1179-1186.

11. Doering-Saad, C., Kampfer, P., Manulis, S., Kritzman, G., Schneider, J., ZakrzewskaCzerwinska, J., Schrempf, H., and Barash, I. 1992. Diversity among Streptomyces strains causing potato scab. Appl. Environ. Microbiol. 58:3932-3940.

12. Faucher, E., Otrysko, B., Paradis, E., Hodge, N C., Stall, R. E., and Beaulieu, C. 1993. Characterization of streptomycetes causing Russett scab in Quebec. Plant Dis. 77:1217-1220.

13. Faucher, E., Savard, T., and Beaulieu, C. 1992. Characterization of actinomycetes isolated from common scab lesions on potato tubers. Can. J. Plant Pathol. 14:197-202.

14. Fridell, J.-E., and Jönsson, U. 1979. En snabb metod för bestämning of resistensen mot vanlig skorv (Streptomyces scabies) hos rädisa [A rapid method for assessing resistance of radish varieties to common scab (Streptomyces scabies)]. Tidskr. Sver. Utsadesforen. 89:233238.

15. Goyer, C., and Beaulieu, C. 1997. Host range of streptomycete strains causing common scab. Plant Dis. 81:901-904.

16. Goyer, C., Charest, P.-M., Toussaint, V., and Beaulieu, C. 2000. Ultrastructural effects of thaxtomin A produced by Streptomyces scabies on mature potato tubers. Can. J. Bot. 78:374380.

17. Goyer, C., Vachon, J., and Beaulieu, C. 1998. Pathogenicity of Streptomyces scabies mutants altered in thaxtomin A production. Phytopathology 88:442-445

18. Healy, F. G., Wach, M., Krasnoff, S. B., Gibson, D. M., and Loria, R. 2000. The $\operatorname{txt} A B$ genes of the plant pathogen Streptomyces acidiscabies encode a peptide synthetase required for phytotoxin thaxtomin A production and pathogenicity. Mol. Microbiol. 38:794804.

19. Keinath, A. P., and Loria, R. 1989. Population dynamics of Streptomyces scabies and other actinomycetes as related to common scab of potato. Phytopathology 79:681-687.

20. Keinath, A. P., and Loria, R. 1991. Effects of inoculum density and cultivar resistance on common scab of potato and population dynamics of Streptomyces scabies. Am. Potato J. 68:515-524.

21. King, R. R., Lawrence, C. H., and Gray, J. A. 2001. Herbicidal properties of the thaxtomin group of phytotoxins. J. Agric. Food Chem. 49:2298-2301.

22. Kinkel, L. L., Bowers, J. H., Shimizu, K., Neeno-Eckwall, E. C., and Schottel, J. L. 1998. Quantitative relationships among thaxtomin A production, potato scab severity, and fatty acid composition in Streptomyces. Can. J. Microbiol. 44:768-776.

23. Kreuze, J. F., Suomalainen, S., Paulin, L., and Valkonen, J. P. T. 1999. Phylogenetic analysis of 16S rRNA genes and PCR analysis of the necl gene from Streptomyces spp. causing common scab, pitted scab, and netted scab in Finland. Phytopathology 89:462-469.

24. Lambert, D. H., and Loria, R. 1989. Streptomyces scabies sp. nov; nom rev. Int. J. Syst. Bacteriol. 39:387-392. 
25. Lawrence, C. H., Clark, M. C., and King, R. R. 1990. Induction of common scab symptoms in aseptically cultured potato tubers by the vivotoxin, thaxtomin. Phytopathology 80:606-608.

26. Leiner, R. H., Fry, B. A., Carling, D. E., and Loria, R. 1996. Probable involvement of thaxtomin A in pathogenicity of Streptomyces scabies on seedlings. Phytopathology 86:709-713.

27. Levick, D. R., Evans, T. A., Stephens, C. T., and Lacy, M. L. 1985. Etiology of radish scab and its control through irrigation. Phytopathology 75:568-572.

28. Lindholm, P., Kortemaa, H., Haahtela, K., Kokkola, M., Salkinoja-Salonen, M., and Valkonen, J. P. T. 1997. Streptomyces spp. isolated from potato scab lesions under nordic conditions in Finland. Plant Dis. 81:13171322.

29. Locci, R. 1994. Actinomycetes as plant pathogens. Eur. J. Plant Pathol. 179:179-200.

30. Loria, R., Bukhalid, R. A., Creath, R. A., Leiner, R. H., Olivier, M., and Steffens, J. C. 1996. Differential production of thaxtomins by pathogenic Streptomyces species in vitro. Phytopathology 85:537-541.
31. Loria, R., Bukhalid, R. A., Fry, B. A., and King, R. R. 1997. Plant pathogenicity in the genus Streptomyces. Plant Dis. 81:836-846.

32. Loria, R., Coombs, J., Yoshida, M., Kers, J. A., and Bukhalid, R. A. 2003. Paucity of bacterial root diseases: Streptomyces succeeds where others fail. Physiol. Mol. Plant Pathol. 62:6572 .

33. Loria, R., and Kempter, B. A. 1986. Relative resistance of potato tubers produced from stem cuttings and seed-piece-propagated plants to Streptomyces scabies. Plant Dis. 70:46-48.

34. Park, D. H., Yu, Y. M., Kim, J. S., Cho, J. M., Hur, J. H., and Lim, C. K. 2003. Characterization of streptomycetes causing potato common scab in Korea. Plant Dis. 87:1290-1296.

35. Powelson, M. L., Johnson, K. B., and Rowe, R. C. 1993. Management of diseases caused by soilborne pathogens. Pages 149-158 in: Potato Health Management. R. C. Rowe, ed. American Phytopathological Society, St. Paul, MN.

36. Rowe, R. C., ed. 1993. Page 178 in: Potato Health Management. American Phytopathological Society, St. Paul, MN.

37. Rozen, S., and Skaletsky, H. J. 2000. Primer3 on the WWW for general users and for biologist programmers. Pages 365-386 in: Bioinformatics Methods and Protocols: Methods in Molecular Biology. S. Krawetz and S. Misener, eds. Humana Press, Totowa, NJ.

38. Sadowsky, M. J., Kinkel, L. L., Bowers, J. H., and Schottel, J. L. 1996. Use of repetitive intergenic DNA sequences to classify pathogenic and disease-suppressive Streptomyces strains. Appl. Environ. Microbiol. 62:3489-3493.

39. Schaad, N. W., Jones, J. B., and Chun, W., eds. 2001 Laboratory Guide for the Identification of Plant Pathogenic Bacteria. American Phytopathological Society Press, St. Paul, MN.

40. Scheible, W., Fry, B., Kochevenko, A., Schindelasch, D., Zimmerli, L., Somerville, S., Loria, R., and Somerville, C. 2003. An Arabidopsis mutant resistant to thaxtomin A, a cellulose synthesis inhibitor from Streptomyces species. Plant Cell 15:1781-1794.

41. Takeuchi, T., Sawada, H., Tanaka, F., and Matsuda, I. 1996. Phylogenetic analysis of Streptomyces spp. causing potato scab based on 16S rRNA sequences. Int. J. Syst. Bacteriol. 46:476-479. 